\title{
The Scottish Diabetes Improvement Plan 2014
}

\author{
JOHN A MCKNIGHT
}

\begin{abstract}
Multiple initiatives are underway to optimise diabetes care in Scotland, led by the Scottish Diabetes Group. These include annual nationwide diabetes surveys, a campaign to increase awareness of signs and symptoms of type 1 diabetes in children ('4Ts'), and a Diabetes Improvement Plan, built around eight key priorities: prevention and early detection of diabetes and its complications; type 1 diabetes care; person-centred care; equality of access; supporting and developing staff; inpatient diabetes care; improving information; and innovation. There is a strong emphasis on empowerment of patients, training and education for staff and patients, and innovative use of data (including provision for healthcare professionals to access their patients' data). Other work is aimed at reducing disparities in outcomes related to ethnicity or socieoeconomic status. Much remains to do, but the introduction of continuous subcutaneous insulin infusion for more patients across NHS Scotland has been of benefit, with early indications that $\mathrm{HbA}_{1 \mathrm{c}}$ might be decreasing slightly in those patients with type 1 diabetes in Scotland. These initiatives take place against a backdrop of an increasing prevalence of diabetes in Scotland, and we hope that these initiatives will build on previous frameworks to promote safe, effective person-centred care across NHS Scotland.
\end{abstract}

Br J Diabetes Vasc Dis 2015;15:131-134

Key words: Diabetes, Care delivery, diabetes register, improving care

\section{Context}

Scotland has a total population of around 5.1 million people. In December 2014, 5.2\% $(276,430)$ were registered as having diabetes. This figure is believed to include around $99.5 \%$ of people diagnosed with diabetes in Scotland.

Healthcare in National Health Service (NHS) Scotland is

NHS Lothian and University of Edinburgh, Scotland, UK

Address for correspondence: Professor John A McKnight Chairman, Scottish Diabetes Group, Consultant Physician, NHS Lothian and University of Edinburgh, Scotland, UK

Tel: +44 (0)1315373072

E-mail: john.mcknight@nhs.net

http://dx.doi.org/10.15277/bjdvd.2015.033
Figure 1. Map of Scotland showing the individual NHS Boards

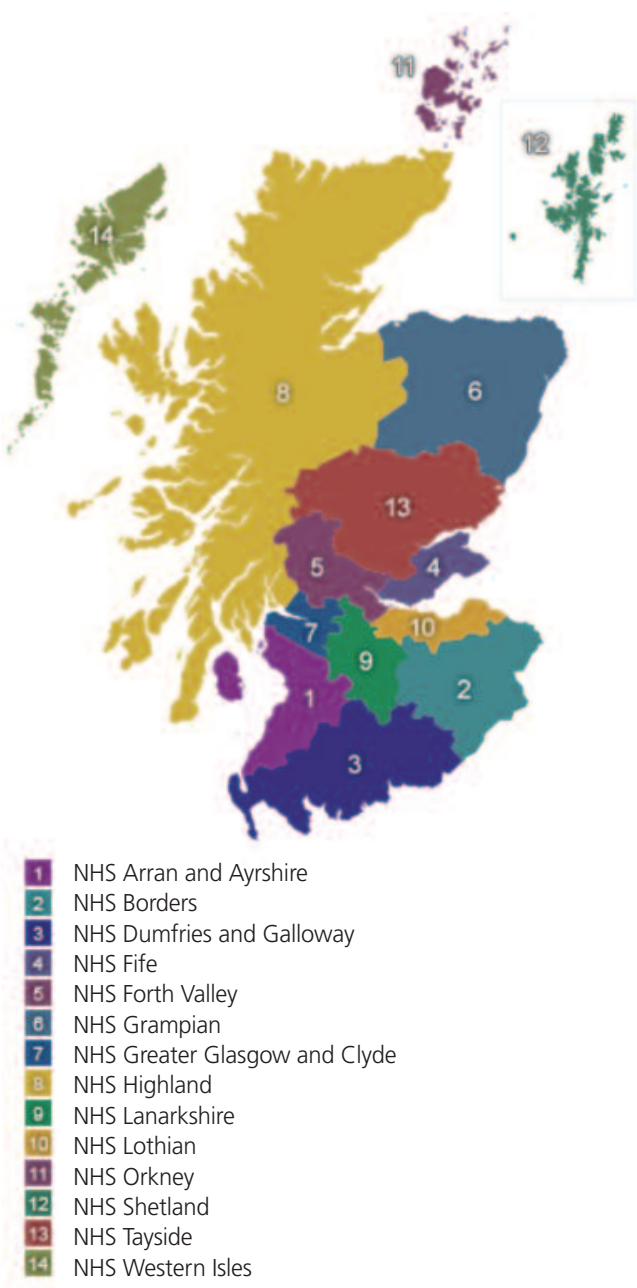

provided through 14 different NHS Boards responsible for populations that vary in size from 21,570 in Orkney to $1,137,930$ in Greater Glasgow and Clyde (Figure 1). Each NHS Board is expected to have a Managed Clinical Network to lead and help deliver diabetes care locally. These networks bring together clinicians, patients and carers to work across traditional boundaries in planning and delivering the equitable provision of highquality, clinically effective diabetes services throughout Scotland. Centrally, this is led and coordinated by the Scottish Diabetes Group and its subgroups that have responsibility for developing 
and delivering previous Diabetes Action Plans (2002, 2006 and 2010') and the new Diabetes Improvement Plan released in November 2014.2

\section{Diabetes Improvement Plan 2014}

There is a major emphasis on improvement within NHS Scotland as described in the NHS Scotland Quality Strategy $(2010)^{3}$ and the Route Map to the 2020 Vision for Health and Social Care (2013). ${ }^{4}$ The new Diabetes Improvement Plan was launched as part of this. The idea of the plan is to build on the previous work described in the Scottish Diabetes Action Plan (2010). ${ }^{1}$

There has already been considerable progress in the last few years in many areas of diabetes care in Scotland, but there is a need to continue the momentum of improvement for many aspects of care for those with diabetes.

Eight priorities were identified in developing the Improvement Plan:

- Prevention and early detection of diabetes and its complications

- Type 1 diabetes

- Person-centred care

- Equality of access

- Supporting and developing staff

- Inpatient diabetes

- Improving information

- Innovation

\section{Prevention and early detection of diabetes and its complications}

The incidence of recorded diabetes in Scotland does not seem to have increased in the last few years (Scottish Diabetes Survey 2013). ${ }^{5}$ This seems to be good news as long as diabetes does not remain undiagnosed. We plan to engage with the Public Health Observatory ${ }^{6}$ to further understand the data on undiagnosed diabetes in Scotland.

Ideas to be developed include the identification and management of those at high risk of developing type 2 diabetes, including those who have had gestational diabetes, the group identified as at high risk due to hyperglycaemia during acute hospital admission, ${ }^{7}$ and methods to record and monitor those with impaired glucose tolerance or impaired fasting glucose.

A campaign aimed at primary care to raise awareness of diabetic ketoacidosis (DKA) was launched in December. At the same time, Diabetes Scotland was promoting its 'Thirsty Tired Thinner Toilet' (4Ts) campaign designed to assist the general public in recognising the symptoms of diabetes in children. ${ }^{8}$ We expect this to increase early recognition and to promote more rapid treatment of new type 1 diabetes, preventing this potentially life threatening complication.

The prevalence of registered diabetes has increased by around 10,000 each year. As the incidence rate does not seem to be increasing, this suggests that those with diabetes are living longer. This could be due to people developing diabetes at a younger age, though our information does not seem to support this. A more likely explanation is that improvements in care have improved survival. The increasing number of people with diabetes and the longer duration of those with the condition further increases pressure on the diabetes services as those with a longer duration of diabetes are more likely to require more therapies (e.g. insulin) and to have a higher risk of complications such as foot disease.

We report annually on our screening for complications in the Scottish Diabetes Survey, which covers all of our registered population. ${ }^{5}$ The 15-month performance for most elements is $85-95 \%$, but we have identified some specific groups that are less likely to receive the required screening. A striking example is the 18-25-year-old group with type 1 diabetes, many of whom (25-35\%) are not having retinopathy screening at the recommended frequency. We intend to feed back screening performance on a quarterly basis to each NHS Board Managed Clinical Network within the improvement plan, while facilitating improved access to their own information relating to most aspects of diabetes care.

\section{Type 1 diabetes}

There is a real need to improve the care and outcomes of all people with type 1 diabetes. We have shown that glycaemic control as measured by $\mathrm{HbA}_{1 \mathrm{c}}$ is not good in Scotland and compares unfavourably with many other developed countries. ${ }^{9}$ The surveys from 2010-2013 reported unchanged results for Scotland, with some variation between NHS Boards, and we have investigated this further by reviewing data from most diabetes centres. Initial analysis revealed a variation between diabetes centres of $14-33 \%$ having an $\mathrm{HbA}_{1 \mathrm{c}}<58 \mathrm{mmol} / \mathrm{mol}$ and $20-42 \%$ having an $\mathrm{HbA}_{1 \mathrm{c}}>75 \mathrm{mmol} / \mathrm{mol}$. Ideas for change have been discussed and one year later there does seem to be some change in the right direction (Table 1). We need to build on this work.

We have had very similar work through our paediatric and adolescent subgroup, who have just launched the DKA prevention campaign mentioned above and also produced some very useful literature for schools. We are also working with Diabetes Scotland to deliver training on youth engagement strategies to healthcare professionals aiming to reduce disengagement.

During the last three years there has been a major increase in the use of continuous subcutaneous insulin infusion, particularly in our paediatric population. This has been useful both for those who receive the therapy and also for the development and skills of the diabetes clinicians. This should have a knock on effect on general care.

\section{Person-centred care}

We need to ensure people with diabetes are enabled and empowered to safely and effectively self-manage by accessing consistent, high quality education and the creation of mutually agreed individualised care plans. This includes increasing access to defined structured education programmes and using approaches for consultations such as House of Care. ${ }^{10}$

Within this we are also going to review and improve our support and care for pregnant women with diabetes.

We are also taking forward work to ensure that patient experience informs both local and national developments in the delivery of diabetes services. 
Table $1 \mathrm{HbA}_{1 \mathrm{c}}$ of type 1 diabetes patients by control category from the Scottish Diabetes Survey (2009-2014)

\begin{tabular}{|c|c|c|c|c|c|c|c|c|}
\hline \multirow[t]{2}{*}{ Year } & \multicolumn{2}{|c|}{$\begin{array}{c}\mathrm{HbA}_{1 \mathrm{c}}<58 \mathrm{mmol} / \mathrm{mol} \\
(7.5 \%)\end{array}$} & \multicolumn{2}{|c|}{$\begin{array}{c}\mathrm{HbA}_{1 \mathrm{c}} 58-75 \mathrm{mmol} / \mathrm{mol} \\
(7.5-9.0 \%)\end{array}$} & \multicolumn{2}{|c|}{$\begin{array}{c}\mathrm{HbA}_{1 \mathrm{c}}>75 \mathrm{mmol} / \mathrm{mol} \\
(9 \%)\end{array}$} & \multirow{2}{*}{$\begin{array}{l}\text { Total } \\
\text { recorded }\end{array}$} & \multirow{2}{*}{$\begin{array}{l}\text { Not } \\
\text { recorded }\end{array}$} \\
\hline & Number & Percentage & Number & Percentage & Number & Percentage & & \\
\hline 2013 & 5,578 & $21.5 \%$ & 10,595 & $40.8 \%$ & 9,788 & $37.1 \%$ & 25,961 & 3,300 \\
\hline 2012 & 5,407 & $21.5 \%$ & 9,830 & $39.1 \%$ & 9,881 & $39.3 \%$ & 25,118 & 3,731 \\
\hline 2010 & 5,337 & $21.8 \%$ & 9,754 & $39.9 \%$ & 9,375 & $38.3 \%$ & 24,466 & 3,444 \\
\hline 2009 & 5,194 & $21.8 \%$ & 9,556 & $40.1 \%$ & 9,096 & $38.1 \%$ & 23,846 & 3,521 \\
\hline
\end{tabular}

\section{Equality of access}

Despite improvements in life expectancy and health outcomes, significant differences still exist for people with diabetes depending on deprivation, where they live, ethnic group and their life circumstances. Ensuring equality of access to health services for all those with diabetes is an important thread that will run through all efforts to improve the quality of services. By doing this we aim to reduce the impact of deprivation, ethnicity and disadvantage on diabetes care and outcomes.

A subgroup of the Scottish Diabetes Group will be formed to address this topic and advise other groups on best practice within these areas.

\section{Supporting and developing staff}

Each interaction between a healthcare professional and a person living with diabetes is an opportunity to enhance motivation and optimise self-management. General Practitioner (GP) trainees are given specific training in consultation skills, but this type of training has not been readily available to most other healthcare professionals. Trained educators are also required to deliver the many different education programmes which are run throughout Scotland.

We are aiming to increase the level of consultation and patient engagement skills across our workforce and increase the level of educator skills and confidence in delivering diabetes education. An important part of this is to build on the previous work of the Psychology in Diabetes, Psychology and Diabetes (PiD/PaD) group ${ }^{11}$ to enhance the levels of psychological assessment skills and methods to deal with issues when identified.

\section{Inpatient diabetes}

The problems with inpatient diabetes care in Scotland are identical to those clearly shown in the national audits of England and Wales. The estimated annual cost of inpatient diabetes care in Scotland was $\mathrm{f} 301$ million between 2005 and 2007, or $12 \%$ of the inpatient budget. We have recognised that improvements in inpatient care are important not only in ensuring person centred care, but from a safety point of view and economically. With this in mind, in collaboration with Healthcare Improvement Scotland we have developed and piloted a Diabetes in Scottish Hospitals initiative to improve glycaemia management called
'Think, Check, Act'12 and aim to spread this across NHS Scotland during the next few years. This is combined with improved foot care awareness and our Check, Protect, Refer campaign aimed at reducing the development of foot ulcers in hospitals.

This development has been supported by some excellent analytical work measuring effectiveness. This needs to be further developed to provide run charts for individual units and hospitals measuring processes of care (e.g. management of hypoglycaemia). We aim to produce these data automatically from linked, downloaded glucose meters within ward areas to support continuous improvement.

\section{Improving information}

Core diabetes information relating to any individual with diabetes is collected automatically from many sources on to our diabetes management system, SCl-Diabetes. These data can then be reviewed by an individual patient through the My Diabetes My Way (MDMW) website ${ }^{13,14}$ or by a clinician caring for the patient, and amalgamated reports can be produced at the level of a GP practice, practice group, hospital clinic, NHS Board or for all of Scotland as reported in the annual Scottish Diabetes Survey. ${ }^{5}$ We therefore have a comprehensive understanding of many aspects of diabetes care in Scotland and have been able to link this to other datasets to gain further information about health outcomes such as mortality and hospital admission. ${ }^{15-18}$

The robust collection of core diabetes information for all people with diabetes in Scotland is a major strength of our organisation. The information is very comprehensive. There is a desire to make these data even more accessible to frontline healthcare professionals through improved design and performance of the user interface.

We will also improve reporting and use of data at national and local levels to further encourage use of the information to improve care. Local users will have an improved ability to review and use their data. Direct availability of a wide range of information for patients is available through the MDMW website which offers the potential to develop a different structure of communication and will, for example, enable some aspects of the House of Care consultation model when patients have access to their results before a consultation. 


\section{Key messages}

- Multiple initiatives are underway to optimise diabetes care in Scotland, led by the Scottish Diabetes Group, centred on a Diabetes Improvement Plan

- Key themes are prevention and early detection of diabetes and its complications; type 1 diabetes care; person-centred care; equality of access; supporting and developing staff; inpatient diabetes care; improving information; and innovation

- The introduction of continuous subcutaneous insulin infusion for more patients across NHS Scotland has been of benefit, with early indications that $\mathrm{HbA}_{1 \mathrm{c}}$ might be decreasing slightly in those patients with type 1 diabetes in Scotland

- We hope that these initiatives will build on previous frameworks to promote safe, effective person-centred care across NHS Scotland

\section{Innovation}

The aim of this priority is to accelerate the development and diffusion of innovative solutions to improve treatment, care and quality of life of people living with diabetes. The increasing number of people with diabetes and the increasing complexity of care relating to therapeutic choices and greater duration of diabetes within this population are placing significant strain on NHS services. Ideas to improve both the quality and efficiency of care are needed urgently. New technologies for communication and information sharing such as MDMW, social media and remote consultation are likely to be required, but within this the concept of individualised care and motivation will have to be protected.

In the last three years, we have greatly increased insulin pump therapy availability and use within Scotland. There is a need to increase this further, and to produce national guidance relating to new continuous glucose monitoring systems and, eventually, closed-loop systems when these become available.

The Scottish Diabetes Group will promote networking and mechanisms to support innovation and will work with others to increase the pace of adoption of proven innovations. This will be challenging but necessary if we are to provide world class diabetes care.

\section{Summary}

In this brief article I have tried to provide a flavour of the Scottish Diabetes Improvement Plan and the priorities identified within it. There is much other important work continuing within diabetes services in Scotland and it will be important to continue with this work, as well as the new priorities. We hope that this will successfully build on previous frameworks to promote safe, effective person-centred care across NHS Scotland.

\section{Conflict of interest None}

Funding I am partly funded by the Scottish Government

\section{References}

1. The Scottish Government. Diabetes Action Plan 2010: Quality Care for Diabetes in Scotland. Available at http://www.gov.scot/Publications/ 2010/08/17095311/0 (last accessed July 2015)

2. The Scottish Government. The Diabetes Improvement Plan. November 2014. Available at http://diabetesinscotland.org.uk/Publications/Diabetes_Improvement_Plan_2014.PDF (last accessed July 2015)

3. The Scottish Government. Quality Strategy. Available at http:// www.gov.scot/Topics/Health/Policy/Quality-Strategy (last accessed July 2015).

4. The Scottish Government. 2020 Vision. Available at http://www.gov.scot/ Topics/Health/Policy/2020-Vision (last accessed July 2015).

5. NHS Scotland. Scottish Diabetes Survey Monitoring Group. Scottish Diabetes Survey 2013 (June 2014). Available at http://www.diabetesinscotland.org.uk/Publications/SDS2013.pdf (last accessed July 2015)

6. The Scottish Public Health Observatory. Available at http://www.scotpho.org.uk/ (last accessed July 2015)

7. McAllister D, Hughes KA, Lone N, et al. Stress hyperglycaemia in hospitalised patients and their 3-year risk of diabetes: A Scottish Retrospective cohort study. PLoS Med 2014;11:e1001708. http://dx.doi.org/10.1371/journal.pmed.1001708

8. NHS Scotland and Diabetes Scotland. Undiagnosed type 1 diabetes in children is a medical mergency. A Healthcare Professionals' guide to an early diagnosis. Available at https://www.diabetes.org.uk/Global/In-YourArea/Scotland/SB_DKAcampaign_A58pp_v7.pdf (last accessed July 2015).

9. McKnight JA, Wild SH, Lamb MJE et al. Glycaemic control of Type 1 diabetes in clinical practice early in the 21st century: an international comparison. Diabet Med 2015;32:1036-50. http://dx.doi.org/10.1111/dme.12676

10. King's Fund. Delivering better services for people with long-term conditions. Building the house of care. Available at http://www.kingsfund.org.uk/sites/files/kf/field/field_publication_file/delivering-better-services-for-people-with-long-term-conditions.pdf (last accessed July 2015).

11. NHS Scotland. Psychology provision in diabetes: the PiD/PaD Project. Available at http://www.diabetesinscotland.org.uk/Publications/PID__PAD_Memo.pdf (last accessed July 2015).

12. NHS Scotland Quality Improvement Hub. Diabetes - think, check, act. Available at http://www.qihub.scot.nhs.uk/safe/diabetes---think-checkact.aspx (last accessed July 2015).

13. NHS Scotland. The My Diabetes My Way website. Available at http://www.mydiabetesmyway.scot.nhs.uk (last accessed July 2015).

14. Cunningham SG, Wake DJ, Waller A, et al. My Diabetes My Way: an electronic personal health record for diabetes. $\mathrm{Br} J$ Diabetes Vasc Dis 2013;13:143-9. http://dx.doi.org/10.1177/1474651413493336

15. Jackson CA, Jones NR, Walker JJ et al. Area-based socioeconomic status, type 2 diabetes and cardiovascular mortality in Scotland. Diabetologia 2012;55:2938-45. http://dx.doi.org/10.1007/s00125-012-2667-1

16. Livingstone SJ, Looker HC, Hothersall EJ, et al. Risk of cardiovascular disease and total mortality in adults with type 1 diabetes: Scottish registry linkage study. PLoS Med 2012;9:e1001321. http://dx.doi.org/10.1371/journal.pmed.1001321

17. Livingstone SJ, Levin D, Looker $\mathrm{HC}$, et al. Estimated life expectancy in a Scottish cohort with type 1 diabetes, 2008-2010. JAMA 2015;313:3744. http://dx.doi.org/10.1001/jama.2014.16425

18. Govan L, Maietti E, Torsney B, et al. The effect of deprivation and HbA1C on admission to hospital for diabetic ketoacidosis in type 1 diabetes. Diabetologia 2012;55:2356-60. http://dx.doi.org/10.1007/s00125-012-2601-6 